\title{
Política de fomento a la economía social en la gobernación del Estado Mérida*
}

\author{
Fuenmayor, Nila del Carmen** \\ Acurero Abreu, Lucrecia***
}

\section{Resumen}

Con la descentralización político-territorial iniciada en 1989 en Venezuela, las Gobernaciones asumen tareas que antes no realizaban, entre éstas se encuentran las de promoción de la economía social. El propósito de este trabajo es explorar la política de economía social en la Gobernación del Estado Mérida. La metodología consistió en el análisis documental y entrevistas abiertas a los funcionarios de la gobernación. Alguno de los resultados dan cuenta de: a) existencia de una propuesta de economía social del gobierno nacional, que constituye un avance importante en materia de justicia social e inclusión de grandes sectores de la sociedad, b) la gobernación ha creado formalmente una política de fomento a la economía social coherente con la nacional. Se concluye que la propuesta de economía social del gobierno de Chávez al ser aprovechada desde los niveles subnacionales de gobierno puede contribuir al avance de la construcción de un modelo de desarrollo alternativo.

Palabras clave: Política Pública, economía social, Consejo Estadal de Planificación y Coordinación de Políticas Públicas, redes, gobernaciones.

\section{Policy to Promote Social Economy in the Governors Office in the State of Merida}

\section{Abstract}

With the political-territorial decentralization policy initiated in Venezuela in 1989, state governors offices assumed work which had not been undertaken by them previously, among others, the

\section{Recibido: 04-12-07. Aceptado: 05-08-24}

* Este trabajo forma parte de los avances del proyecto: Políticas de Apoyo de las Gobernaciones a la Economía Social. Programa Política y Administración subnacional, adscrito al Centro de Estudios de la Empresa (CEE) de la Universidad del Zulia (LUZ). Financiado por el Consejo de Desarrollo Científico y Humanístico de LUZ.

** Lic. en Trabajo Social, Magíster en Intervención Social. Investigadora del (CEE), (FCES) de (LUZ). Acreditada en el Programa de Promoción al Investigador (PPI) del Ministerio de Ciencia, Tecnología e Innovación. E-mail: ncfuenmayor@yahoo.com

*** Socióloga, Candidata a Magíster en Gerencia Pública, Docente de la Universidad Bolivariana de Venezuela. E-mail: lucreciacurero@yahoo.com 
promotion of social economy. The purpose of this paper is to explore economic social policy in the State of Merida. The methodology is documentary analysis and open interviews with state officials. The results indicate that a) there is a socio-economic proposal on the part of the national government which constitutes an important advance in the areas of social justice and inclusion of large segments of the society, and b) state governments have formally created a policy to promote a coherent social economy in relation to the national economy. The conclusion is that the social-economic proposals of Chavez when implemented at the sub-national level, can contribute to advances in the construction of a model of alternative development.

Key words: Public policy, social economy, State Council of Public Policy Planning and Coordination, networks, state governments.

\section{Introducción}

A partir de la década de los 90 se inició el proceso de descentralización en Venezuela, como respuesta a las demandas del nuevo modelo de desarrollo de corte neoliberal. Este proceso encontró fundamentación jurídica en el artículo 137 de la hoy derogada constitución nacional, el cual establecía la descentralización administrativa mediante la atribución de determinadas materias de competencia nacional a los Estados y Municipios.

De esta manera, se comienzan a desarrollar procesos en correspondencia con la descentralización político-administrativa: la elección de los gobernadores y Alcaldes por medio de la votación directa y secreta, sustituyendo el nombramiento del gobernador por parte del Presidente de la República y la transferencia a los Estados con carácter exclusivo de algunas competencias nacionales, así como un conjunto de competencias sociales en condiciones concurrentes.

El proceso de descentralización administrativa tuvo un impacto importante en el ámbito subnacional, sobre todo en las gobernaciones, puesto que les fueron transferidas ciertas competencias que anteriormente eran manejadas por instancias Nacionales. Esto tiene implicaciones de tipo político-administrativas, pero no logró que la ciudadanía accediera a las decisiones relacionadas con los asuntos públicos que le afectan, siendo éste uno de los aspectos que abanderaba el proceso de descentralización, limitándose a fortalecer la democracia representativa con la posibilidad de elegir a los gobernadores y alcaldes.

Un impulso importante en función de superar algunas debilidades del proceso de descentralización, se da con la Constitución de la República Bolivariana de Venezuela (CRBV), (ANC, 1999), al profundizar cambios a nivel administrativo que tuvieron repercusiones favorables en los niveles subnacionales, al abrir la posibilidad de que estos desarrollen ciertas áreas contempladas como estratégicas en el modelo de desarrollo a implantar, como es el caso específico de la Economía Social.

Aunado a esto la CRBV promueve una transformación de las relaciones entre la sociedad civil y el Estado, por medio de ciertos mecanismos que permiten el acercamiento de la ciudadanía a los procesos decisorios de la política pública. En tal sentido, Kapron y Fialho, citados en Hintze (2003:7), plantean que: "...el proceso de elaboración e implementación de 
políticas públicas para la economía social permite la ampliación de espacios de interacción entre estado y sociedad organizada, extrapolando los limites de actuación de la esfera estatal a través de la construcción de asociaciones de interés mutuo...entre instituciones gobernantes y entidades civiles...".

Los mecanismos que establece la CRBV, son un factor fundamental de acercamiento entre los ciudadanos y las instancias que definen la política en el ámbito subnacional como es el caso de los Consejos Estadales de Planificación y Coordinación de Políticas Públicas (CEPCPP) en cada uno de los estados (art.166), y de los Consejos Locales de Planificación pública (CLPP) en el ámbito municipal (art.182), que constituyen instancias de planificación participativa.

La gobernación del Estado Mérida ha asumido y potenciado todos estos cambios propuestos a nivel nacional, promoviendo en diferentes momentos y desde diferentes instancias un apoyo sostenido a la economía social, por medio de la Contraloría del Consejo Legislativo, específicamente, desde la Subcomisión de Apoyo y Promoción a la Economía Social y Alternativa, utilizando como instancia al Consejo Estadal de planificación y coordinación de políticas públicas (CEPCPP), desarrollando la propuesta de economía social en el Plan de desarrollo del estado Mérida en el cual se puede aprecia como un aspecto fundamental para alcanzar el desarrollo económico y social de la región, y finalmente a través del la Dirección de economía popular que, en la actualidad, promueve y desarrolla todo lo relacionado con la economía social.
El propósito de este trabajo es explorar la política de economía social de la Gobernación del Estado Mérida. La economía social va a ser entendida en este trabajo, como lo plantea Bastidas (2002:9) citando a Cháves y Monzón como el "...conjunto de empresas privadas creadas para satisfacer las necesidades de sus socios a través del mercado, produciendo bienes y servicios, asegurando, financiando, y en las que la distribución del beneficio y la toma de decisiones no están ligadas directamente con el capital aportado por sus socios...". Este tipo de organizaciones posee una estructura de funcionamiento acorde con principios y valores relacionados con la solidaridad, la igualdad, el trabajo colectivo y beneficios compartidos, además de un basamento jurídico especifico, lo cual las diferencia de las empresas del sector privado y de las organizaciones del sector público; también son denominadas empresas del tercer sector. Son organizaciones de la economía social las empresas familiares, las cooperativas, las mutuales y las microempresas, entre otras.

Partimos del supuesto que en lo estados cuyas gobernaciones comparten el mismo proyecto político del gobierno nacional, la política de economía social se desarrolla de manera coherente y articulada, y en correspondencia a la política nacional, lo cual potencia las posibilidades de ejecución de la política en cuanto al apoyo y la cooperación entre organismos nacionales y la gobernación.

\section{De la Economía de mercado a la Economía Social}

La adopción de la teoría económica neoliberal ha provocado nefastas expe- 
riencias en América Latina. La reencarnación de la "mano invisible" del mercado que según Adam Smith mantendría el equilibrio en la economía, era un sueño del cual despertamos más empobrecidos; de allí que cada día se multiplican las críticas en el ámbito internacional del llamado "Neoliberalismo salvaje".

Resumiendo los planteamientos de Torres $(2002: 12,13)$ el "catecismo neoliberal" se basa en cuatro postulados básicos: a) la supremacía del mercado como espacio que determina las relaciones sociales sin la intervención del Estado, y al margen de la política, b) se privilegia al individuo por encima de las colectividades, por consiguiente hay una negación de las relaciones cooperativas y solidarias, puesto que prevalece el interés propio, c) el lucro privado es el detonante de la actividad humana encaminada a satisfacer necesidades, de allí que se fortalezca la ganancia privada en por encima de los beneficios sociales, d) las categorías económicas son el eje central del discurso y de las prácticas sociales. Este "catecismo neoliberal" ha sido una falacia económica y fracasó en los gobiernos que lo han implantado. En el caso de países como México, Chile, Argentina, Venezuela, entre otros, su aplicación generó el incremento de la pobreza y la desigualdad social y sobre todo, el incremento desproporcionado de la exclusión social.

En el libre juego de la oferta y la demanda, bases fundamentales del neoliberalismo y por supuesto en la no intervención del estado, se anula al sujeto colectivo y se privilegia a un individuo "teórico" que esta en constante competencia con el otro para satisfacer sus necesidades en el mercado. El neoliberalismo tie- ne un potente discurso ideológico avalado por poderosas instituciones internacionales, interesadas en mantener el status quo, académicos e intelectuales reconocidos, políticos influyentes y empresarios, entre otros.

El neoliberalismo como propuesta económica profundiza el desplazamiento del factor social y se exacerba el enfoque de la economía como un asunto únicamente vinculado al mercado y en función del crecimiento del capital. Sin tomar en cuenta lo que acertadamente plantea Maza Zavala (2002), citando a Kliksberg "La economía no es simple problema de creación de riqueza, sino de hacer de ella un medio eficaz para el bienestar de los pueblos, para la erradicación de la pobreza, para la integración social, para el acceso en igualdad de oportunidades a los bienes terrenales del hombre y la mujer".

La economía no puede estar de espaldas a la gente, precisamente porque las decisiones económicas que se adopten en un país, afectan las condiciones de vida y la cotidianidad de grandes grupos humanos, la mayoría de las veces perjudica más a los que menos poseen, quedando aislados y desprotegidos frente a un mundo donde cada vez resulta más difícil sobrevivir bajo la ley del más fuerte, establecida por un modelo de competencia salvaje.

El desarrollo económico en un país democrático, con un proyecto político basado en la gente, necesariamente tiene que construir un modelo, que privilegie el desarrollo humano, sobre todo, "tejer el desarrollo en torno a las personas y no las personas en torno al desarrollo" (Castañeda, 1994:17). En este sentido, algunos autores como Verano y Bernal (1998: 92) 
plantean que "... Al margen y en contravía del neoliberalismo... persisten..., crecen y se desarrollan otras corrientes del pensamiento social completamente distintas, que están confluyendo desde diversas direcciones para articular y configurar una cosmovisión, un proyecto histórico y un metarrelato emancipador, más universal y más acorde con un devenir de la historia basado en el progreso humano integral y es el humanismo social".

En el anterior sentido, Bastidas y Richer (2001:9) siguiendo a Lévesque y Mendell plantean que "La economía social sería la que reconozca las dimensiones sociales de la economía... designa a la vez un enfoque teórico sobre economía, y también un tipo de organizaciones, basadas en la democracia y el empresariado colectivo". Para ello el factor Humano y la asociatividad son fundamentales como elemento de articulación de los procesos de trabajo. En tal sentido, Kliksberg plantea la asociatividad como área del capital social y la define como: "la capacidad de una sociedad de generar todo tipo de formas de cooperación, de sumar esfuerzos, las famosas sumas donde todo el mundo puede ganar, desde las formas de cooperación más elementales..., hasta los más sofisticados modelos de organizaciones cooperativas" (Kliksberg, 2001:17).

Coraggio (2004:286) afirma que "esta economía es social porque produce sociedad y no sólo utilidades económicas, porque genera valores de uso para satisfacer necesidades de los mismos productores o de sus comunidades generalmente de base territorial, étnica, social y cultural y no está orientada por la ganancia y la acumulación del capital sin limites. Porque vuelve a unir producción y reproducción, al producir para satisfacer de manera más directa y mejor las necesidades acordadas como legítimas por la misma sociedad".

Los sujetos que participan en las organizaciones de la economía social desarrollan sus actividades en sus espacios vitales de vida, vinculadas a su identidad social y cultural, esto marca la diferencia con el tipo de actividad propia de la empresa capitalista y fundamentalmente con las relaciones de trabajo que se desarrollan alrededor de la misma.

Resumiendo los planteamientos de Coraggio (2004: 286), podemos decir que una actividad productiva es considerada propia de la economía social, si presenta las siguientes características: a) Construcción de espacios de acción constituidos por individuos, familias, comunidades y colectivos que actúen combinando la utilidad material y valores de solidaridad y cooperación, limitando, más no anulando, la competencia, b) Conformación de mercados donde los precios y las relaciones resulten de una matriz social que pretenda la integración de todos con un esfuerzo y unos resultados distribuidos de manera igualitaria, c) Consolidación de acciones colectivas en ámbitos locales, donde los conflictos de intereses y la competencia pueden ser regulaos de manera más transparentes, d) Constitución de asociaciones libres de trabajadores en lugar de empresas donde el trabajo está supeditado al capital autoritario por la necesidad de obtener un salario para sobrevivir.

La Economía social admite el mercado "... por su antigüedad y validez como instrumento económico que ha existido y avanzado conforme al desarro- 
llo de la humanidad, pero de ninguna manera como el regulador de las relaciones humanas" (Verano y Bernal, 1998: 20).

Este enfoque humanista de la economía social brinda a la población alternativas de organización en función de actividades productivas; bajo relaciones de igualdad y solidaridad, por lo cual constituye una alternativa a las relaciones de competencia mercantilista que fomenta el mercado capitalista. Una de las organizaciones más representativas de todo este movimiento económico y social son las cooperativas, definidas como: "una asociación autónoma de personas que se han unido de forma voluntaria para satisfacer sus necesidades y aspiraciones económicas, sociales y culturales en común mediante una empresa de propiedad conjunta y de gestión democrática" (García, 1998:1). De allí que las empresas asociativas se basan, fundamentalmente en los principios cooperativos, los cuales son contrarios a los que rigen las prácticas económicas propias del modelo de acumulación capitalista.

\section{Política de apoyo a la Economía Social en el gobierno bolivariano: El contexto nacional}

El modelo de desarrollo económico, basado en las bondades de la renta petrolera, que imperó en Venezuela durante más de cuarenta años, auspiciado por los vicios de la Democracia Representativa, se caracterizó por ser monoproductor, dependiente del capital transnacional, de los bienes y la tecnología extranjera, además generador de exclusión social, pobreza, miseria y desempleo es- tructural, concentración de la propiedad en manos de las élites políticas y económicas dominantes y un pesado e ineficiente aparato burocrático que alejaba al ciudadano de sus instituciones.

El anterior escenario ha cambiado drásticamente en los últimos cinco años, sobre todo por los cambios y transformaciones importantes que se han dado en la vida económica, política y social del país, todo esto en un marco de luchas y enfrentamientos de dos posiciones que aún en la actualidad parecen irreconciliables, al mismo tiempo los sectores populares, tradicionalmente excluidos de nuestra sociedad, se han ido organizando alrededor de diferentes iniciativas, sobre todo de actividades productivas desarrolladas por empresas asociativas, fundamentalmente de cooperativas que cuentan con un rango constitucional, leyes e instituciones que las respaldan, a diferencia de lo que sucedía en el año 1989, en el contexto de aplicación de las medidas de ajuste estructural que privilegiaban las microempresas, por encima de otras formas asociativas, esto en correspondencia con las postulados neoliberales negadores de la asociatividad, la solidaridad, la ayuda mutua y propulsores de la competencia en el mercado. En este sentido Barrastes (1997:86) plantea que la entonces llamada economía popular no sólo se redujo en esa época al sector de las microempresas, sino que aunado a ello el sector no contó con el ordenamiento jurídico, ni administrativo que hiciera de este tipo de economía una política integral de estado.

Las políticas del gobierno nacional se han ido formulando, gestionando y consolidando en medio de un fuego cru- 
zado producto de la confrontación de diferentes actores en pugna por intereses políticos y económicos. "en la sociedad se libra una lucha hegemónica entre actores reunidos en dos polos que portan proyectos políticos sustancialmente distintos, y que hasta la fecha se perciben como excluyentes" (López, 2004:106).

En 1998, Hugo Chávez Frías, en medio de una contienda política encarnizada presenta su programa de gobierno en el cual se vislumbran algunos lineamientos de lo que, posteriormente, constituiría la política de apoyo a la economía social, en tal sentido se plantea como parte de una política social integradora "...el impulso de estrategias productivas solidarias que trasciendan el hecho netamente económico y permitan romper con las desigualdades. Para esto es necesario el desarrollo y crecimiento del trabajo calificado y eficiente que permita la organización de unidades productivas para competir en los mercados laborales en condiciones ventajosa (microempresas, cooperativas, PYMI)" (Movimiento V República, 1998:16).

En 1999, ya electo como presidente de la República, Hugo Chávez Frías, presenta, el programa económico de transición 1999-2000 (Coordiplan, 1999:1), cuyo objetivo era: "...promover el crecimiento sostenido y diversificado de la economía, reducir la inflación y aumentar el nivel de empleo productivo para proteger el poder adquisitivo de las familias", se plantea el fortalecimiento de las pequeñas y medianas industrias y empresas (PyMls/PyMEs) así como de las microempresas y cooperativas como una de las estrategia para impulsar el sector industrial y la economía en general, para lo cual contempla programas para la creación y desarrollo de este tipo de asociaciones productivas, con el objetivo de superar el apoyo asistencial y transformarlas en formas de acceso de amplios sectores de la población al mercado y como una vía de participación popular, proponiéndose como proyectos pilares el plan de desarrollo de la microempresa y el plan de desarrollo de las cooperativas.

En el Programa económico 2000, se expresa que: "La política de desarrollo de los sectores productivos está dirigida al fortalecimiento de las pequeñas y medianas empresas, las microempresas y cooperativas, la cual contribuirá al mejoramiento de la calidad del empleo existente y al incremento de la demanda de nuevos empleo. En tal sentido la estrategia de financiamiento desempeñará un papel decisivo, al centralizar, en el Banco Industrial de Venezuela, el financiamiento hacia las Pymes/Pymis y el desarrollo de programas crediticios, con mecanismos novedosos..., ejecutados por el Banco del pueblo" (MPD, 2000b: 29).

De igual manera el Plan operativo Nacional (2000), que se estructura de acuerdo a cinco equilibrios fundamentales: social, económico, político, territorial e internacional, establece como parte fundamental de la política industrial (equilibrio económico), el apoyo y la modernización de las PyMI, las cooperativas y microempresas por medio de programas de financiamiento. Se propone como organismo responsable de esta estrategia al Ministerio de producción y comercio (MPD, 2000a: 23).

Como otro aspecto importante está el compromiso que asume el Estado venezolano en la protección y promoción de las 
asociaciones cooperativas, las empresas familiares, las microempresas, etc. garantizando la capacitación, la asistencia técnica y el financiamiento oportuno.

Es de observar que el cooperativismo ha sido dentro de las organizaciones de la economía social, el que mayor apoyo ha recibido de parte del gobierno de Chávez, lo cual se puede constatar en un insistente discurso presidencial que impulsa la conformación de cooperativas a lo largo y ancho del país como una manera efectiva de enfrentar la pobreza, el desempleo y las formas negativas de economía informal. Lo cual contribuiría a constituir un sector económico diferente del estatal y del privado tradicional, que a la vez profundice la democracia y la organización de los ciudadanos en torno a problemas de empleo, producción, alimentación, vivienda, entre otros.

De igual manera, el Plan de desarrollo económico y social de la nación 2001-2007, desarrolla los principales lineamientos de la política de Economía social. En el Plan se establecen cinco grandes equilibrios (económico, social, políti$\mathrm{co}$, territorial e internacional) para alcanzar el desarrollo y se afianza en la necesidad de construir la nueva república por medio de la participación protagónica y la inclusión social de las grandes mayorías.

En el mencionado Plan la economía social es definida como el "...sector de producción de bienes y servicios que compagina intereses económicos y sociales comunes, apoyado en el dinamismo de las comunidades locales y en una participación importante de los ciudadanos y de los trabajadores de las llamadas empresas alternativas, como son las em- presas asociativas y las microempresas autogestionables" (MPD, 2001:27).

El desarrollo de la economía social se describe en el equilibrio económico y se basa en dos programas fundamentales: "...democratización del capital y la legitimación del mercado a través de actividades productivas autogestionarias donde converjan formas de propiedad distintas, tales como microempresas, empresas comunitarias, nuevas cooperativas, pequeñas y medianas empresas, y empresas campesinas...El otro programa complementario al anterior, se refiere a la organización de un sistema de microfinanzas, ley de cooperativas, Banco del Pueblo Soberano, Banco de la Mujer y el sistema financiero público, orientado a facilitar el acceso a los recursos financieros y la asistencia técnica a las comunidades populares, y autogestionarias, empresas familiares y microempresas, que facilitará la promoción y desarrollo de los beneficiarios de la economía social" (MPD, 2001:27).

El Plan de la Nación del gobierno bolivariano no sólo plantea el apoyo financiero por medio de un sistema de microfinanzas que facilite el acceso a los recursos económicos del estado, con pautas crediticias flexibles que tomen en cuenta las condiciones y necesidades del sector de la economía social, también considera la asistencia técnica, programas masivos de capacitación en todas las áreas que fortalezcan el sector de la economía social, apoyo para el desarrollo tecnológico para aumentar la productividad y la competitividad, apoyo para la comercialización y gestión de negocios por medio de la incorporación de este tipo de organizaciones a los programas de com- 
pras de bienes y servicios por parte del Estado, fomento de la organización y conformación de nuevas empresas de la economía social y expansión de ramas de actividad, entre otras.

Otro impulso importante que recibe la economía social, en el gobierno de Hugo Chávez Frías, lo constituye la plataforma legal que regula el sector de la economía social. Además de lo establecido en la Constitución de la República Bolivariana de Venezuela (CRBV) de 1999, se aprueban: La ley Especial de Asociaciones Cooperativas (LEAC), (AN, 2001) y el decreto con fuerza de ley de Creación, Estímulo, Promoción y Desarrollo del Sistema Microfinanciero (Presidencia de la República, 2001).

Tenemos entonces que la CRBV encabeza la base legal que promueve la economía social en el país; en su artículo 70 plantea "Son medios y protagonismo del pueblo en ejercicio de su soberanía.... en lo social y económico las instancias de atención ciudadana, la autogestión, la cogestión, las cooperativas en todas sus formas incluyendo las de carácter financiero, las cajas de ahorro, la empresa comunitaria y demás formas asociativas guiadas por los valores de la mutua cooperación y la solidaridad".

Asimismo la CRBV, contempla en su art. 118 "... el derecho de los trabajadores y trabajadoras, así como de la comunidad para desarrollar asociaciones de carácter social y participativo, como las cooperativas, cajas de ahorro, mutuales y otras formas asociativas" vinculadas a actividades económicas. En el mismo artículo se establece el respeto por las especificidades de las organizaciones cooperativas, por el trabajo asociado y su ca- rácter generador de beneficios colectivos; tales como el empleo y el bienestar social general.

En el anterior sentido el insistente discurso presidencial ha impulsado la conformación de cooperativas a lo largo y ancho del país como una manera efectiva de enfrentar la pobreza, el desempleo y las formas negativas de economía informal. Lo cual contribuiría a constituir un sector económico diferente del estatal y del privado tradicional, que a la vez profundice la democracia y la organización de los ciudadanos en torno a problemas de empleo, producción, alimentación, vivienda, entre otros.

La LEAC tiene como objetivo establecer las normas generales para la organización y el funcionamiento de las cooperativas y de los organismos de integración, refiriéndose a éstos últimos como aquellos que agrupan a las cooperativas para sumar fuerzas, ya bien sea por sector o tipo de servicios que presten o por ubicación territorial. Por otro lado regula la relación del sector cooperativo con el resto de las organizaciones de la economía social y con el Estado, incluyendo el papel y autoridad otorgada a la Superintendencia Nacional de cooperativas (art. 77 al 85).

La LEAC establece en su Artículo 2 que: "Las cooperativas son asociaciones abiertas y flexibles, de hecho y derecho cooperativo, de la Economía Social y Participativa, autónomas, de personas que se unen mediante un proceso y acuerdo voluntario, para hacer frente a sus necesidades y aspiraciones económicas, sociales y culturales comunes, para generar bienestar integral, colectivo y personal, por medio de procesos y empresas de 
propiedad colectiva, gestionadas y controladas democráticamente." Esta definición de cooperativa engloba las características generales del cooperativismo, sin embargo no logra diferenciarla del resto de las formas asociativas. Enfatiza el aspecto colectivo de las mismas, cuando las caracteriza como empresa de propiedad colectiva; reconoce su finalidad en cuanto al bienestar integral tanto individual como universal; $y$ sus diversas formas de actividades a desarrollar, donde se distinguen no sólo las económicas sino también las sociales y culturales, pero todos estos aspectos son atribuibles también a otras formas de asociación pertenecientes a la economía social, por lo cual no se logra establecer una diferencia clara desde el punto de vista conceptual.

En cuanto a la relación con el Estado se distinguen los medios y mecanismos de promoción y protección necesarios para asegurar a las cooperativas la participación protagónica en materia social y económica establecida en el Art. 118 de la CRBV. La LEAC enumera en su Art. 89 , los siguientes mecanismos de promoción de las cooperativas: apoyo a sus planes de desarrollo; establecimiento de sistemas de formación, capacitación y de acreditación, difusión de experiencias a través de los diferentes medios de comunicación; estímulo a las cooperativas; preferencia de compras y venta de bienes y servicios, y en concesiones públicas; fortalecimiento de sistemas financieros propios; la exención de impuestos nacionales o directos, y el fortalecimiento de sistemas de protección social, entre otros.

Otro aspecto con respecto al apoyo que ofrece el Estado a la economía so- cial, está previsto en el artículo 308 de la CRBV, que establece: "el estado protegerá y promoverá la pequeña y mediana industria, las cooperativas, las cajas de ahorro, así como también la empresa familiar, la microempresa y cualquier otra forma de asociación comunitaria del trabajo, el ahorro y el consumo, bajo el régimen de propiedad colectiva, con el fin de fortalecer el desarrollo económico del país, sustentándolo en la en la iniciativa popular. Se asegurará la capacitación, la asistencia técnica y el financiamiento oportuno".

Este artículo de la constitución generó cierta controversia, puesto que ubica a la PYMI, como una empresa de la economía social, lo cual es una contradicción, puesto que tal y como lo plantean López y Ochoa (2002:426) "...existen diferencias considerables entre las formas de organización típica mercantil y las organizaciones de la economía social, que plantean un sentido y una filosofía distinta a esta forma de regulación estatal, aspecto que se constituye en un riesgo político para un proyecto transformador que procura tomar distancia de la supremacía que el capital tuvo en los procesos de administración privada y pública predominante".

En cuanto al traslado de competencias, la LEAC en su Art. 87, establece claramente: "las cooperativas como formas de organización de la comunidad, podrán ser sujetos de transferencia de la gestión de los servicios públicos, previa demostración de su capacidad para prestarlos. A tal efecto, estos podrán otorgarse en concesión en los términos previstos en la ley especial que regula esta materia".

La ley de Creación, Estímulo, Promoción y Desarrollo del Sistema Microfi- 
nanciero constituye un avance importante en materia de economía social en Venezuela, puesto que establece los lineamientos legales de financiamiento para este sector. Esta ley tiene por objeto, según lo establece el artículo 1: "Crear, estimular y desarrollar el sistema microfinanciero, para atender la economía popular y alternativa, a los fines de su incorporación a la dinámica del desarrollo económico y social". Esta ley en su artículo 2, define el sistema microfinanciero como el "conjunto de entes u organizaciones públicas y privadas que mediante el otorgamiento de servicios financieros y no financieros; fomenten, promocionen, intermedien o financien tanto a personas naturales, como a personas jurídicas organizadas en unidades asociativas o microempresas, en áreas rurales y urbanas".

De igual manera en su artículo 8, establece la creación del Fondo de Desarrollo Microfinanciero, adscrito al Ministerio de Finanzas, que tiene por objeto, "...el apoyo de las políticas de fomento , desarrollo y fortalecimiento del sistema financiero".

El artículo 15 de esta ley, establece los requisitos para el otorgamiento de créditos, los cuales se basan en criterios flexibles que permitan a las empresas de la economía social acceder a créditos del estado y de otras organizaciones. Dentro de los requisitos se encuentran: 1) El análisis crediticio, basado en el conocimiento de la persona, la voluntad moral para honrar sus obligaciones, su unidad económica familiar, el entorno social y sus potencialidades. 2) La flexibilización de los requisitos y facilitación en los trámites administrativos. 3) El incremento progresivo de los montos de los préstamos al usuario, en función del cumplimiento de los pagos; y 4) Los créditos serán otorgados, con o sin intereses, fundamentándose en la oportunidad, la necesidad de acceso inmediato y el tiempo de recuperación de los mismos.

Las evidencias empíricas derivadas de la investigación demuestran que dentro de las cooperativas de ahorro y crédito, esta ley se ha transformado en un marco importante para regular sus formas de financiamiento, $y$ les ha permitido recuperar y reinvertir su capital, al mismo tiempo que fortalecen las actividades de productores agrícolas, artesanos, entre otros, la mayoría de ellos asociados en cooperativas.

Es necesario destacar que fue creada a nivel nacional toda una estructura institucional que permite el desarrollo de la política hacia el sector de la economía social. Dentro de los cuales destaca el Ministerio de Economía Popular (MINEP), que tal y como queda planteado en el numeral 9 de su decreto de creación, plasmado en Gaceta Oficial del 16 de Septiembre, tiene por objeto formular "...las políticas para el fomento de la economía popular, estimulando el protagonismo de las cooperativas, cajas de ahorro, empresas familiares, microempresas, y otras formas de asociación comunitarias para el trabajo, el ahorro y el consumo bajo el régimen de propiedad colectiva sustentada en la iniciativa popular" (MINEP, 2004:3). Este ministerio tiene como entes adscritos: El Fondo de Desarrollo Microfinanciero (FONDEMI), la Superintendencia Nacional de Cooperativas (SUNACOOP), el Instituto Nacional de Cooperación Educativa (INCE), El Instituto Nacional de Desarrollo Social y Rural 
(INDERURAL), el Fondo único social y la Fundación Banco del Pueblo Soberano, entre otros.

La política de apoyo del gobierno bolivariano a la economía social, prevista en leyes, programas, planes y otros documentos, se traduce sobre todo en la conformación y consolidación de organizaciones cooperativas. Según la SUNACOOP desde el año 1998 hasta agosto de 2005, el número de asociaciones cooperativas agrupadas pasó de 762 a 79.775 (SUNACOP, 2005) lo que representa un incremento de $10.469,16 \%$.

Al respecto debemos considerar que el incremento de las cooperativas en sí mismo no da cuenta de los aspectos cualitativos, pero si del creciente apoyo crediticio que está otorgando el Estado a este tipo de asociaciones, el cual ha dado paso al oportunismo de quienes crean cooperativas para acceder a créditos, de dónde surge la pregunta: ¿cooperativas para acceder a créditos o créditos para fortalecer las cooperativas?

De igual manera las evidencias empíricas de la investigación demuestran que muchas de las cooperativas conformadas no tienen claro la razón social de su creación, lo cual produce una perversión en el desarrollo de verdaderos procesos de economía social, y que se han generado crecientes procesos de corrupción favorecidos por la centralización de los trámites para la conformación de cooperativas y el surgimiento de "gestores" compran las reservas de nombres y constancias en complicidad con los funcionarios de la máxima instancia cooperativa.

Al respecto el Superintendente de SUNACOP, Carlos Molina afirma que en un primer operativo se pudo constatar que hay más de 100 cooperativas que presentan vicios relacionado con los valores neoliberales, que van en contra de la solidaridad y el apoyo mutuo. De igual manera afirma que se está violando no sólo la LEAC, sino también la Ley Orgánica del Trabajo, dentro de alguno de los vicios que menciona se encuentran: a) Uso de la figura de cooperativas para eludir responsabilidades propias de la relación laboral y para reducir costos y maximizar las ganancias, b) Descuido de la elaboración de libros contables, c) Conformación de cooperativas para obtener créditos sin un plan de trabajo. A esto se le agrega los vicios al interior de la SUNACOOP, tales como cobro por los trámites, complicidad con gestores, etc. (ABN, 2005). Actualmente se está desarrollando el Plan Nacional de Fiscalización para subsanar los vicios que se vienen presentando y se tiene previsto el posible cierre de entre 1500 y 2000 cooperativas para el último trimestre del año (ABN, 2005).

Todo lo anterior no le resta importancia a las crecientes experiencias que se vienen dando en diferentes estados del país, sobre todo en aquéllos, cuyos gobernadores comparten el mismo proyecto político del gobierno nacional, y que por lo tanto siguen los lineamientos de la política nacional en materia de Economía Social y además da muestra de una intención real de adecentar los procesos relacionados con este sector de la economía.

\section{Apoyo de la gobernación del Estado Mérida a la economía social}

El Estado Mérida jugó un papel protagónico en la organización de una agen- 
da alternativa para una economía con rostro humano o economía social, en la discusión que se generó en el país con motivo del proceso de conformación de la Asamblea Nacional Constituyente, en el cual el movimiento cooperativo Venezolano (MCV) asume un papel protagónico y "...formuló una serie de propuestas que exigían para las cooperativas la concesión constitucional de los mismos derechos económicos que las empresas privadas poseían. Entre los ocho artículos propuestos por el MCV se encontraba el término Economía Social (ES) y es así, como al lograr que sus propuestas fuesen casi integralmente incluidas en la Constitución Nacional (CN), la ES, al igual que el término mutuales, obtuvo rango constitucional...(Bastidas, 2002: 2).

La promoción de la economía social, las empresas asociativas, cooperativas, microempresas y unidades de producción económica, fueron adquiriendo mayor importancia en el marco de los acontecimientos registrados en el ámbito nacional, a los cuales hicimos referencia en el apartado anterior, pero las iniciativas asociativas y de organización, sobre todo de cooperativas adquirieron un mayor impulso desde el año 2000 con el Gobernador Florencio Porras, perteneciente a la misma corriente política del Presidente Hugo Chávez Frías.

\subsection{Apoyo desde el Consejo Legislativo}

El apoyo a la economía social en el estado Mérida, se inició desde la Contraloría del Consejo Legislativo (en su mayoría en manos de partidarios del oficialismo) específicamente, desde la Subcomi- sión de Apoyo y Promoción a la Economía Social y Alternativa, por iniciativa de los miembros afectos al proceso revolucionario, por medio del Consejo Estadal de Planificación y Coordinación de Políticas Públicas (CEPCPP), instancia desde la cual se desarrolla toda la propuesta de economía social que forma parte del Plan de desarrollo del estado Mérida y finalmente desde la Dirección de Economía Popular en la cual se integran todas las propuestas relacionadas con la economía social.

La comisión de Contraloría del Consejo Legislativo del Estado Mérida, específicamente, desde la Subcomisión de Apoyo y Promoción a la Economía Social y Alternativa promovió diferentes procesos de apoyo a la economía social, dentro de las cuales destacan:

- "Elaboró propuestas para la Comisión de Asambleístas encargada de lo relacionado con la Economía Social (este proceso se desarrolló en todo el país) para ser incorporadas a la CRBV. Lo cual representó un respaldo a las iniciativas de Economía Social, que conquistan una fuerte presencia en la Constitución. La elaboración de estas propuestas tuvo lugar con base en reuniones, foros, debates, participación directa de productores, asociaciones civiles, organizaciones no gubernamentales, cooperativistas, microempresarios, representantes de instituciones públicas, entre otros,

- "Liderizó el debate para la elaboración de la LEAC. por medio de foros, talleres, encuentros, entre otras actividades, donde participaron cooperativistas de los 23 municipios del esta- 
do, con la finalidad de dar aportes a la comisión del Ministerio de la Producción y Comercio y de la SUNACOOP, equipo encargado de presentar una propuesta de ley para su aprobación por parte del Consejo de Ministros.

- "Una vez publicada la LEAC, se inició un proceso de socialización de la información de los aspectos de la nueva ley, por medio de foros, asambleas y talleres de capacitación sobre los principios y valores cooperativos, y presentación del programa de asistencia técnica, financiamiento y acompañamiento desde las instituciones de la gobernación del Estado.

- Inició un proceso de capacitación en diseño y formulación de proyectos de inversión, de acuerdo al área que se proponían trabajar las organizaciones de la economía social y al impacto económico, social, cultural y ambiental que iba a producir en el desarrollo de la región, tomando en cuenta los lineamientos y metodología sugeridos por los diferentes entes de financiamiento. Se determinó en los talleres la factibilidad de cada proyecto, y se establecieron las posibles instituciones de apoyo financiero. Todo este proceso contó con la participación activa de las organizaciones vinculadas a la economía social.

- Elaboró una propuesta de conformación de una Red de Apoyo Institucional a la Economía Social , como una instancia de alianzas estratégicas y de articulación entre todos los organismos vinculados con el sector para ofrecer un apoyo consistente a la Economía Social Alternativa. La propuesta de la red de apoyo institucio- nal, responde a la necesidad de darle una plataforma institucional a la economía social, en la cual confluyan todas las instituciones nacionales y regionales que tienen programas relacionados con este tipo de economía alternativa.

Este proceso de apoyo e impulso a la economía social por parte del Consejo Legislativo, va a ser complementado en el año 2002, a raíz de la aprobación de la ley del CEPCPP (AN, 2002).

\subsection{Apoyo desde el Consejo Estadal de Planificación y Coordinación de Políticas Públicas}

El Consejo Legislativo del Estado Mérida (2003) promulga el reglamento para el funcionamiento de los CEPCPP, definidos como "... el órgano del poder público en el Estado Mérida, encargado de la planificación de las políticas públicas del Estado, así como de la coordinación de la participación y cooperación entre los entes gubernamentales, la comunidad organizada y los ciudadanos", desde el punto de vista político, económico y social representan una instancia para instrumentar el modelo de democracia participativa.

Es importante resaltar que el mencionado reglamento estableció la economía social como parte del sistema económico del Estado, que debe ser impulsada de acuerdo a las especificidades de la región. En concordancia con esto, la gobernación de Mérida ha hecho mayor énfasis en propiciar la articulación y coordinación entre los diferentes sectores de la economía social, lo cual implicó necesariamente el fortalecimiento e involucramiento de 
diversos actores en la formulación y diseño de esta política pública.

Las reuniones y discusiones desarrolladas en el marco de la I y II Plenaria del Consejo Estadal de Planificación y Coordinación de Políticas Públicas, dieron como resultado la formulación y diseño del Plan de Desarrollo del Estado Mérida que surge de con el fin de articular de manera coherente la propuesta de desarrollo regional al Plan de desarrollo económico y social de la Nación 2001-2007 (CEPCPP, 2003).

En la elaboración de los lineamientos generales del Plan de desarrollo del estado Mérida se parte de la concepción de los equilibrios que establece el Plan Nacional: equilibrio social, económico, político, territorial y el internacional, se le agrega el equilibrio interestatal e interregional. La economía social se ubica en el equilibrio económico, y se establece como parte de este sector la pequeña y mediana empresa (PYME), y el cooperativismo.

En el sentido anterior se incurre en el mismo error de la CRBV y en el Plan de desarrollo económico y social de la Nación, al incluir dentro del sector de la economía social a la pequeña y mediana empresa (PYME), puesto que como se explicó anteriormente, son empresas con fines de lucro, que obedecen a una lógica estrictamente capitalista de contradicción capital-trabajo y en muchos casos promueven procesos de sobreexplotación de los trabajadores, lo cual no está en sintonía con el modelo de igualdad e inclusión social que se pretende construir desde el gobierno de Hugo Chávez Frías. Al respecto no negamos el apoyo a la pequeña y mediana empresa, contrariamente creemos que deben ser fortaleci- das, puesto que juegan un papel importante dentro del desarrollo económico y social de la nación, pero desde estrategias dirigidas al sector privado, con fines de lucro, sin las prerrogativas de las organizaciones de la economía social.

Para las PYMES se plantean varias líneas estratégicas, tales como: a) Propiciar una relación integral entre los sectores productivos, responsables del desarrollo de la economía estadal, b) Propiciar una relación integral entre los sectores productivos, responsables del desarrollo de la economía estadal, c) Desarrollar el proceso de modernización de las PYMES, d) Aplicar Políticas de seguimiento y control para el otorgamiento de créditos y e) Elaborar, conjuntamente con los sectores público y privado, políticas y estrategias de capacitación y adiestramiento, orientadas al incremento de la productividad y competitividad para todos los sectores económicos (CEPCPP, 2003).

Estos aspectos relacionados con el apoyo a las PYMES entran en contradicción con el propósito de alcanzar un nuevo modelo de democracia participativa y protagónica en el cual el desarrollo endógeno, se erige como proyecto alternativo que reconoce al sujeto, los valores, la cultura, lo propio como puntal del desarrollo, proponiendo la transformación profunda de las estructuras económicas y sociales, incorporando la sustentabilidad, la economía social, fomentando las solidaridades locales, la convivencialidad, la conciencia ecológica, el papel protagónico del sujeto y la organización popular, como contraparte de la productividad y la competencia exacerbadas propias del modelo neoliberal.

En cuanto al sector del cooperativismo se establece, en primer lugar, la 
capacitación en organización, participación y administración; y, en segundo lugar, el financiamiento, la producción y el mercadeo, y se realiza un diagnóstico del Cooperativismo en la región, por medio del cual se determinan varios problemas, dentro de los cuales se mencionan: a) Inexistencia de una relación vinculante entre el movimiento cooperativista y el sector gubernamental, b) Débil estructura organizativa del movimiento cooperativo a nivel regional, escasos recursos humanos especializados para expandir la organización de cooperativas, c) Ausencia de políticas del Sector gubernamental con relación a la Promoción, Constitución y Apoyo financiero al Cooperativismo regional y d) Falta de visión de las cooperativas como fuente generadora de empleos y bienestar social, entre otras (CEPCPP, 2003).

Dentro de las líneas estratégicas se proponen: a) Implementar en el Sistema Escolar, programas de capacitación y formación en materia de cooperativas, b) Elaborar el Plan Estratégico de Cooperativismo Integral y c) Disminuir la burocratización administrativa en el proceso de creación de Cooperativas (CEPCPP, 2003).

Se establecen las siguientes líneas de acción a) Cultivar dentro del Sistema Escolar, en sus niveles básico, medio, diversificado y superior, valores y principios propios del cooperativismo, b) Crear los Consejos de Coordinación de Cooperativismo para todos los niveles gubernamentales, c) Promover proyectos ante los CLPP para las transferencias de competencias y servicios a las cooperativas, impulsar programas de financiamiento adecuado y oportuno, d) Crear un equipo interinstitucional, encar- gado de la promoción y capacitación en materia cooperativista a las comunidades organizadas, e) Crear y fortalecer la Red de Cooperativas de la Región, crear en el Estado, la sede descentralizada de la Superintendencia Nacional de Cooperativas (CEPCPP, 2003).

Como hemos podido observar, la política de economía social en el estado Mérida, ha sido construida de acuerdo a los lineamientos que establece la política nacional, y apoyándose en los instrumentos legales, creados para tal fin. Pero de manera dispersa desde diferentes instancias, en virtud de la necesidad de concentrar en una institución todos lo esfuerzos relacionados con el desarrollo de la economía social en la región, se crea mediante decreto № 269, el 15 de noviembre de 2004 la Dirección de Economía Popular (DEP).

\subsection{Apoyo desde la Dirección de Economía Popular (DEP) de la gobernación}

La DEP tiene como propósito el impulso de los mecanismos que permitan la transformación del modelo económico en el Estado, en función de la construcción del modelo de desarrollo endógeno socio-popular, impulsado por el gobierno nacional y que privilegia al Cooperativismo en toda la región. La dirección fue diseñada por una comisión designada por el Gobernador, para diseñar sus objetivos, funciones y organización, misión, visión, etc. Dentro de los objetivos de esta dirección se encuentran: a) Incidir en una participación más justa en la distribución de la riqueza, b) Compaginar los intereses económicos con los sociales para 
ampliar y desarrollar la economía de la región, c) Impulsar la Mérida productiva, apoyando las iniciativas de los merideños, promoviendo espacios y oportunidades a la vocación productiva de las comunidades, d) Auspiciar la democratización del crédito, e)Garantizar la seguridad alimentaria agroalimentaria, f) Apoyar las comunidades locales para la conformación y consolidación de empresas alternativas, empresas asociativas y las microempresas autogestionables.

La estructura organizativa de la dirección está conformada por las siguientes unidades: Coordinación de economía social, coordinación de finanzas social y departamento de asesoría jurídica.

\subsubsection{La Coordinación de Econo- mía Popular}

Tiene los siguientes objetivos específicos: a) Evaluar las capacidades productivas de la comunidad y potencialidades de la región; a través de visitas de inspección y atendiendo la información e investigaciones realizadas por otras instituciones, b) Promover las políticas de financiamiento de la Dirección de Economía Popular, así como también, de aquellas instituciones con las cuales se hayan suscrito convenios, b) Brindar asesoría a la comunidad organizada en asociaciones cooperativas, bancos locales, PyMES y PyMIS; en el desarrollo de alternativas de inversión, que garanticen su viabilidad y factibilidad económica, c) Llevar a cabo la recuperación crediticia (DEP, 2004). Dentro de los programas de esta coordinación se encuentran los siguientes:

- "Atención al Soberano: diseñado en función de organizar el proceso de solicitudes de parte de los ciudadanos que requieran información sobre el cooperativismo y los requisitos básicos para constituir una cooperativa. Permite un acercamiento entre los funcionarios y los interesados en conformar unidades asociativas.

- "Creación de Redes de Cooperativas: Este programa propicia la integración y participación de las cooperativas de la región, así como el diseño de propuestas para la consolidación de la economía social en función de promover el desarrollo endógeno.

- "Bancos Locales se diseñó con la finalidad de estimular la democratización de los recursos económicos que requieren las unidades asociativas de producción (cooperativas, empresas familiares, etc.), las Pequeñas y Medianas Empresas (PYMES) y las Pequeñas y Medianas Industrias (PYMIS). Los Bancos Locales se conciben como una asociación civil sin fines de lucro, con personalidad jurídica propia, constituida por habitantes de una comunidad, bajo los principios de ayuda mutua, solidaridad social y cooperativismo.

- "Mérida Solidaria de Alimentos (MESA). Es un Programa diseñado para incorporar a las unidades productivas asociativas en la provisión de alimentos para la región, y una forma de implementar lo referido a la política alimentaría.

- "Creación de Unidades de Economía Popular: Son un equipo de personas pertenecientes a las Unidades de Batalla Endógena (UBE) y Patrulleros Sociales que se responsabilizan para impulsar la transformación del mode- 
lo económico del Estado hacia uno endógeno, socio-popular y participativo.

- "Instalación de Núcleos de Desarrollo Endógeno: La Dirección de Economía Popular estimulará un nuevo modelo económico que se enmarca en las necesidades y potencialidades reales en la búsqueda de una economía más democrática; en la que participen y ganen todos por igual. Para esto, se parte de la vocación productiva de las regiones y las capacidades de las comunidades, quienes organizadas en redes productivas, serán las primeras en beneficiarse del trabajo colectivo. Se requiere estimular la producción nacional con el trabajo y la participación de todos, buscando elevar la calidad de vida, orientándose en cinco ejes: industria, agricultura, turismo, infraestructura y servicios.

\subsubsection{La Coordinación de finan- za social}

Esta coordinación tiene como objetivo ejecutar las políticas de fomento, promoción y recuperación microfinanciera para el desarrollo de las comunidades, por medio de las organizaciones de carácter social y participativo, que permitan el desarrollo de la economía social en el estado. Esta coordinación tiene los siguientes programas:

- "Alianzas Estratégicas: Diseñado para establecer convenios de cooperación institucional y alianzas estratégicas con los diversos entes crediticios públicos y privados regionales y nacionales, entre ellos: Fondo Merideño para el Desarrollo Económico Sustentable (FOMDES), Banco de fo- mento regional de los Andes (BANFOANDES), Banco Industrial de Venezuela, Banco de desarrollo económico y social de Venezuela (BANDES), Banco del pueblo soberano (BPS) Instituto Nacional para la pequeña y Mediana Industria (INAPYMI), Fondo de la Pequeña y Mediana Industria (FONDEMI), entre otros). Así como también organismos públicos y privados que tengan como función el desarrollo integral de las asociaciones productivas.

- "Créditos: Este programa tiene como objeto recibir, evaluar, tramitar y darle celeridad a las solicitudes realizadas por las comunidades organizadas, PYMES, PYMIS, así como también otorgar asistencia técnica y financiera que permita su reinserción en el campo laboral y productivo de aquellas personas excluidas por el antiguo modelo económico.

- "Mérida productiva: Dirigido a promover la participación y corresponsabilidad del sector público y privado para potenciar la fuerza productiva de la región, impulsando el modelo de desarrollo endógeno, utilizando el potencial del estado, y fomentando la distribución equitativa del ingreso y la riqueza, bajo los principios de igualdad, estabilidad, y desarrollo humano integral.

\subsubsection{Departamento de Asesoría Jurídica}

Creado con el objeto de proporcionar asesoría jurídica a la misma institución (DEP) y a las comunidades, sobre todo a cooperativas y otras formas asociativas con el fin de orientarlos en el procedimien- 
to legal correspondiente para su constitución y funcionamiento, posee tres programas: a) Asesoría jurídica que ofrece todos sus servicios de manera gratuita a la comunidad organizada en sus diferentes formas, tales como: cooperativas, Consejos Parroquiales y Municipales de Economía Popular, microempresas, otras, b) Elaboración de documentos cuyo objetivo es ofrecer asistencia técnica directa para la adquisición de personalidad jurídica, una vez que haya recibido toda la asesoría correspondiente., c) El programa de Documentos y Convenios busca establecer alianzas estratégica con otras instituciones para ejecutar los proyectos de las diferentes formas asociativas.

Los programas promovidos por la DEP se desarrollan a través de las siguientes estrategias:

a. Promoción organizativa:

La DEP promueve la conformación de organizaciones de la Economía social, fundamentalmente cooperativas; para ello recibe y atiende toda solicitud de comunidades y grupos interesados en emprender iniciativas asociativas alrededor de alguna actividad productiva. Estas solicitudes son atendidas por personal de la DEP, tanto en las oficinas de esta institución como en las comunidades que manifiesten interés, allí se les brinda información sobre cooperativismo, su importancia en el desarrollo económico de la región, y como forma de enfrentar la pobreza. De igual manera se le ofrece un acompañamiento desde el inicio hasta que logran constituirse legalmente, brindándoles la asesoría necesaria para tal fin.

b. Capacitación:

Diseñada para desarrollar procesos de Capacitación dirigida al área del
Cooperativismo, específicamente en lo que respecta al manejo de conceptos propios del movimiento cooperativo, las ventajas de la conformación de cooperativas, los procedimientos legales para su constitución legal. Todo esto con la finalidad de estimular la conformación de nuevas cooperativas. De igual forma se prevén procesos de capacitación para las cooperativas constituidas para que puedan alcanzar las metas y objetivos propuestos.

\section{c. Financiamiento:}

Tiene como finalidad recibir, evaluar, tramitar y darle celeridad a las solicitudes de créditos realizadas por las comunidades organizadas, PYMES, PIMYS, así como también asesoría para la elaboración del presupuesto del proyecto de inversión. Dentro de los requisitos para el otorgamiento de créditos a las cooperativas, se encuentran: Acta constitutiva, Rif, Nit, fotocopia de cedula de los asociados, Registro de la asamblea donde los asociados autorizan para la realización de solicitud de crédito, fianza solidaria entre los socios, cotizaciones de los activos que se estén solicitando.

La DEP, financia el área de producción y servicios, haciendo énfasis en las actividades agrícolas, para las cuales se estipulan créditos de hasta cien millones de bolívares. En el área de servicios se aprueba hasta 20 millones de Bolívares, que vendría siendo 9132,4 dólares. Actualmente no se financian las áreas de Transporte Público y Turismo, porque generalmente las propuestas exceden el máximo de financiamiento establecido por la DEP. En estos casos se les asesora sobre cómo acceder a los créditos de Banco de desarrollo económico y social 
de Venezuela (BANDES), Instituto Nacional para la Pequeña y mediana Industria (INAPYMI), Fondo de crédito Industrial (FONCREI) entre otros, que son entes nacionales y con recursos propios para turismo.

En cuanto al pago de los créditos se estipula el tiempo de acuerdo a la producción o la prestación de servicios, pero no puede exceder los cinco años. Las tasas de interés son al $6 \%$ anual por cuotas fijadas según el ingreso y el egreso que la cooperativa estime en su proyecto.

La DEP, no maneja recursos económicos para créditos, realiza toda la evaluación, aprueba el proyecto y la solicitud de crédito y luego la remite al Fondo Merideño de Desarrollo Sustentable (FOMDES), el cual recibe los recursos directamente de la gobernación y los asigna a las cooperativas designadas por la $D E P$, de igual manera se encarga de la recuperación del crédito, aunque la DEP, se encarga del seguimiento y acompañamiento de la cooperativa en la ejecución del proyecto.

Todo este proceso que se ha planteado a lo largo del trabajo, permite establecer que la articulación de la gobernación del estado Mérida a los lineamientos de la economía social trazados a nivel nacional, ha generado un ambiente propicio para el crecimiento, la consolidación y el fortalecimiento sobre todo del sector cooperativo en este estado. Esto en si mismo no evita conflictos entre los diferentes actores involucrados, pero si garantiza una cierta coherencia entre las directrices de las instituciones nacionales y las diferentes instancias que en el nivel subnacional apoyan las diferentes iniciativas que surgen en el ámbito de las organizaciones de la economía social, lo cual disminuye lo que López y Ochoa (2002:427) mencionan sobre los riesgos políticos que "...estarían dados por los obstáculos que interpongan los gobiernos subnacionales para poner en práctica las orientaciones alternativas centrales...".

Por supuesto que hay otros obstáculos que los actores colectivos deben enfrentar; el clientelismo, la corrupción, el partidismo, entre muchos otros, que suelen estar presentes en cualquier instancia nacional o subnacional de la administración pública. Como plantea acertadamente Coraggio (2003:3) "no se trata de tener el "poder" para cambiar la realidad, sino de construir nuevos poderes, nuevas capacidades de toda la sociedad y su Estado...".

En este sentido, la economía social no sólo es una vía para la construcción y desarrollo de iniciativas económicas que pueden beneficiar a amplios sectores de la población sino también se erige como un espacio importante para potenciar la participación, que no debe verse de parte de quienes gobiernan como impedimento, puesto que realmente se constituye en "un recurso indispensable en la época de transición en incertidumbre por la que atravesamos, para que la economía no se defina a espaldas de la gente, sino que la incorpore como actor político, social y económico fundamental. Por lo demás, la solidaridad, la cooperación y la participación no son una restricción al interés particular, son potentes instrumentos para lograrlo" (Coraggio, 2003:11).

\section{Conclusiones}

El sector de la economía social, requiere una necesaria vinculación con el 
Estado como ente que formula, diseña y ejecuta políticas públicas, específicamente las económicas. De allí que su papel es fundamental en la construcción y desarrollo de esta nueva lógica de economía alternativa que lleva implícito en sus objetivos el mejoramiento de la calidad de vida de la población, el Estado está obligado a establecer alianzas estratégicas entre las diversas formas de organización, así como también a promover las decisiones colectivas para hacer efectiva la democracia participativa. De igual manera es necesario que impulse la creación de redes de innovación y producción en el sector de la economía social, creando condiciones para generar, desde dichas redes, tecnología alternativa, a partir de las propias capacidades internas del país.

Venezuela se erige como referencia para otros países de América latina, en cuanto al apoyo que ofrece el Estado a las organizaciones de la economía social en materia de financiamiento, capacitación, asistencia técnica y promoción, entre otras, esto se puede constatar en el crecimiento acelerado de las cooperativas en el país, miles de iniciativas colectivas que reciben financiamiento de entes públicos para desarrollar actividades productivas diversas y que les permiten a la población enfrentar de una manera digna lo estragos de la pobreza. Iniciativas que se presentan como alternativas para resolver las necesidades que no satisface un mercado capitalista basado en el lucro, la competencia, y la productividad y que deja de lado valores relacionados con la solidaridad, la ayuda mutua, las relaciones igualitarias, etc. Es el apoyo al trabajo asociativo como contraparte de las relaciones laborales basadas en la peor aberración de la humanidad "la explotación del hombre por el hombre", basado el poder que da ser el propietario de los medios de producción. Es el resultado de una estrategia para enfrentar la pobreza que a pesar de que tiene debilidades, posee la fortaleza de la voluntad política para desarrollarla, y la intención de que se mantenga una relación dialógica y de co-aprendizaje entre Estado y sociedad.

La propuesta de economía social del gobierno bolivariano, constituye un avance importante en materia de justicia social e inclusión de grandes sectores de la sociedad a procesos productivos de carácter asociativo, y genera nuevas estructuras y capacidades organizativas, que si son aprovechadas desde los niveles subnacionales de gobierno, tenderán a construir el modelo de desarrollo alternativo, sustentable, autogestionario y humanista al cual se aspira en la Constitución de la República Bolivariana de Venezuela, y en el cual el desarrollo endógeno, se presenta como una propuesta ideal para aprovechar nuestros recursos en todas sus formas, un desarrollo alternativo que rescata los valores, y propone una profunda transformación cultural, económica y social.

La gobernación del Estado Mérida ha creado formalmente una política de fomento a la economía social coherente con la nacional, tomando sus basamentos de lo establecido en la CRVB, la Ley Especial de Asociaciones Cooperativas y del Plan de desarrollo económico y social de la Nación (2002-2005). En este sentido, el desarrollo de la Economía Social en los términos previstos en el ámbito nacional, se inicia en estado Mérida, en princi- 
pio impulsada por miembros del Consejo legislativo afectos al proyecto bolivariano, luego se retoma con fuerza desde la gobernación por medio del Consejo Estadal de Planificación y Coordinación de Políticas Pública, y finalmente desde la Dirección de Economía Popular. Esta vinculación gobierno nacional- gobierno regional ha favorecido la articulación de instituciones y de procesos, así como también las relaciones de cooperación interinstitucional, lo cual se puede constatar por las diversas experiencias exitosas que han surgido en este estado y que han sido apoyadas directamente por la gobernación.

\section{Referencias Bibliográficas}

Asamblea Nacional Constituyente (1999), Constitución de la República Bolivariana de Asamblea Nacional (2001). Ley Especial de Asociaciones Cooperativas. Gaceta oficial N³7.28.

Asamblea Nacional (2002), Ley de los Consejos Locales de Planificación Pública. Caracas.

Venezuela. Gaceta oficial N 5.453. Caracas.

Agencia Bolivariana de Noticias (ABN) (2005), Cerca de 2 mil cooperativas podrían ser cerradas por SUNACOP. Disponible en http://www.abn.info.ve/go news5.php? articulo $=17274 \&$ lee $=18$, 3 de Septiembre.

Bastidas Delgado (2002), Hacia una política de Estado para el desarrollo de la Economía Social en Venezuela. Consideraciones a propósito de la posible creación del cargo de Ministro de Estado o Ministerio para la Economía Social. Ponencia presentada en el III Simposio Nacional de Economía Social. Centro Interdisciplinario de Investigación, Formación y Documentación de la Economía Cooperativa, social y Pública (CIRIEC). Barquisimeto. Venezuela.

Bastidas Delgado, Oscar y Richer, Madeleine (2001), "Economía Social y Economía Solidaria: intento de una definición" En Revista Venezolana de economía social CAYAPA. Año1 №1. Mayo. Pp. 7-32.

Barrantes César (1997), El apoyo de a la Economía Popular en Venezuela ¿Hacia una política social orgánica de Estado? Fondo Editorial Tropykos. Caracas. Venezuela.

Castañeda, Jorge G. (1994), La Utopía Desarmada. Intrigas, dilemas y promesa de la izquierda en América Latina. Tercer Mundo Editores. Bogotá, Colombia.

Congreso de la República de Venezuela (1989), Ley Orgánica de descentralización, Delimitación y Transferencia de Competencias del poder público.

Consejo Estadal de Planificación y Coordinación de Políticas Públicas (2003), Lineamientos Generales del Plan de Desarrollo del Estado Mérida. Documento oficial.

Consejo Legislativo del Estado Mérida (2003), Reglamento de funcionamiento y debates del Consejo Estadal de Planificación y Coordinación de Políticas Públicas. Gaceta oficial del Estado Mérida № 524.

COORDIPLAN (1999), Programa económico de transición del gobierno de Hugo Chávez Frías 1999-2000. Documento, Caracas.

Coraggio José Luis (2003), Las políticas públicas participativas: ¿obstáculos o requisitos para el desarrollo local? Disponible en http://riles.ungs.edu.ar/documentos/78_las_políticas_públicas_participativas.pdf, 14 de Mayo.

Coraggio José Luis (2004), De la emergencia a la estrategia: más allá del alivio de la pobreza. Primera edición. Buenos Aires. 
Documento Institucional. Dirección de Economía Popular (2004), Mérida. Venezuela.

García Müller, Alberto (1998), Marco Jurídico del Modelo de Economía Solidaria. En El modelo de Economía Solidaria. Una alternativa frente al Neoliberalismo. Publicado por la confederación Latinoamericana de Cooperativas y Mutuales de Trabajadores. Bogotá. Colombia.

Hintze, Susana (2003), Estado y políticas públicas: Acerca de la especificidad de la gestión de políticas para la economía social y solidaria. Disponible en http://www.aaeap.org.art/ponencias/ congreso2/Hintze, 21 de Junio

Kliksberg, Bernardo (2001), El Capital Social. Caracas-Venezuela.

López Carrasco, Carlos Eduardo y Ochoa Henríquez Haydée (2002), Políticas subnacionales de fomento a la economía social en Venezuela. En Revista de Ciencias Sociales . VIII. № 3 . Universidad del Zulia. Facultad de Ciencias Económicas y Sociales. Maracaibo, Venezuela.

López Maya, Margarita (2004), Venezuela 2001-2004: Actores y estrategias. En Cuadernos del Cendes. Año 21. № 56. Venezuela, Caracas.

Ministerio de Planificación y desarrollo (MPD)(2000a), Plan operativo Nacional (2000).

Ministerio de Planificación y Desarrollo (MPD) (2000b), Programa económico 2000.

Ministerio de Planificación y Desarrollo (MPD) (2001), Lineamientos generales del plan de desarrollo económico y social de la nación. Caracas. Venezuela. Documento Oficial.
Ministerio de Economía Popular (2004),Disponible en http://www.minep.gov.ve./ quienes_somos/misionvision.htm

Movimiento V República (1998), Programa de gobierno "La propuesta de Hugo Chávez para transformar a Venezuela". Caracas.

Presidencia de la República de Venezuela (2001), Ley de Creación, Estímulo, Promoción y Desarrollo del Sistema Microfinanciero. Gaceta Oficial № 37.164. Decreto № 1.250 .

Superintendencia Nacional de Cooperativas (2005), El cooperativismo venezolano navega en el mar del capitalismo. Disponible en http://www.com.ve/noticias/imprimir . asp? id=46586.

Torres López, Juan (2002), El neoliberalismo. Sociedad, Trabajo y poder financiero. Editores Vadell. Caracas. Venezuela.

Verano Páez, Luís Francisco y Bernal Escobar, Alejandro (1998), Elementos ideológicos y políticos del Modelo de Economía Solidaria. En El modelo de Economía Solidaria. Una Alternativa frente al Neoliberalismo. Publicado por la Confederación Latinoamericana de Cooperativas y Mutuales de trabajadores. Bogotá. Colombia.

Zavala, Maza (2000), El problema de la pobreza a fines del siglo XX. En Revista Venezolana de Economía y Ciencias Sociales, Vol. 6 № 3. Universidad Central de Venezuela (UCV). Caracas. Venezuela. 